"Atomic force microscopy and voltammetric investigation of quadruplex formation between a triazole-acridine conjugate and guanine-containing repeat DNA sequences". Chiorcea-Paquim, A. M., Pontinha, A. D., Eritja, R., Lucarelli, G., Sparapani, S., Neidle, S., Oliveira-Brett, A. M. Anal. Chem., 87(12), 6141-6149 (2015). doi: 10.1021/acs.analchem.5b00743.

\title{
Atomic force microscopy and voltammetric investigation of quadruplex formation between a triazole-acridine conjugate and guanine-containing repeat DNA sequences
} Ana-Maria Chiorcea-Paquim ${ }^{1}$, Ana Dora Rodrigues Pontinha ${ }^{1}$, Ramon Eritja ${ }^{2}$, Genny Lucarelli $^{3}$, Silvia Sparapani ${ }^{3}$, Stephen Neidle $^{3}$, Ana Maria Oliveira-Brett ${ }^{1 *}$

${ }^{1}$ Department of Chemistry, University of Coimbra, Portugal

${ }^{2}$ Institute for Research in Biomedicine, IQAC-CSIC, CIBER-BBN Networking Centre on Bioengineering, Biomaterials and Nanomedicine, Barcelona, Spain

${ }^{3}$ UCL School of Pharmacy, University College London, London WC1N 1AX, UK.

ABSTRACT: The interactions of the Tetrahymena telomeric repeat sequence d(TG4T) and the polyguanylic acid $(\operatorname{poly}(\mathrm{G}))$ se-quence with the quadruplex-targeting triazolelinked acridine ligand GL15 were investigated using atomic force microscopy (AFM) at a highly oriented pyrolytic graphite and voltammetry at a glassy carbon electrode. GL15 interacted with both sequences, in a time dependent manner and G-quadruplex formation was detected. AFM showed the adsorption of quadruplexes as small d(TG4T) and poly $(\mathrm{G})$ spherical aggregates and large quadruplex-based poly $(\mathrm{G})$ assemblies, and voltammetry showed the decrease and disappear-ance of GL15 and guanine oxidation peak currents, and appearance of the G-quadruplex oxidation peak. The GL15 molecule strongly stabilized and accelerated G-quadruplex formation in both $\mathrm{Na}+$ and $\mathrm{K}+$ ioncontaining solution, although only $\mathrm{K}+$ promoted the formation of perfectly aligned tetramolecular G-quadruplexes. The small-molecule complex with the d(TG4T) quadruplex is discrete and approximately globular, whereas the G-quadruplex complex with poly $(\mathrm{G})$ is formed at a number of points along the length of the polynucleotide, analogous to beads on a string.

\section{Introduction}

The telomeres are responsible for the protection of the chromosomes ends, being involved in greater than $80 \%$ of all cancers. One of the key steps in human carcinogenesis is the activation of the telomeres maintenance system that allows the continued proliferation of cancer cells.

G-quadruplexes (GQs) are four-stranded higher-order structures formed by folding of a single (intra-molecular) or by the intermolecular association of two, three or four separate gua-nine rich DNA strands. ${ }^{1-7}$ The core motif of the GQ is the G-quartet, a planar grouping of four $\mathrm{G}$ bases held together by eight Hoogsteen hydrogen bonds. G-quartets self-associate by $\pi-\pi$ hydrophobic stacking interactions, which are further stabilised by 
the presence of monovalent cations, notably sodium and potassium, which coordinate the O6 substituent atom of each guanine base and form a cation channel in the interior of a GQ structure. The occurrence of GQ sequences in telomeres, promoter regions and other genomic locations ${ }^{8,9}$ was deter-mined by the direct visualisation of GQ formation in cell nuclei, in the cytoplasm and at telomeres, ${ }^{10,11}$ which revealed the crucial role of these structures as targets for anticancer drugs.

A large number of potent GQ-binding ligands which stabilize or promote GQ formation have been described in the literature. ${ }^{12-15}$ The GQ ligands in telomeres prevent GQ from unwinding and opening the telomeric ends to telomerase, thus indirectly targeting the telomerase enzyme complex and inhibiting its catalytic activity. Some GQ ligands have shown significant telomerase inhibition or suppression of the transcription activity of oncogenes, thus entering in clinical trials for cancer therapy.

Acridines are heterocyclic compounds some of which have been used as chemotherapeutic agents in human cancer. A number of acridine derivatives have been specifically synthesized with the purpose of increasing binding affinity and selectivity for human telomeric DNA quadruplexes. ${ }^{16-20}$ In particular the GQ-targeting acridine derivatives BRACO-19 and RHPS4 have been important tools for studying the antitumor activity of this general class of agents. However, they are relatively non GQ-selective, having also significant binding affinity for duplex DNA. ${ }^{18}$ More recently, a series of triazole-linked acridine ligands, e.g. GL15 (Scheme 1A), with enhanced selectivity for human telomeric GQs binding versus duplex DNA binding have been designed, synthetized and evaluated. ${ }^{19}$

Scheme 1 - Schematic representations: (A) the triazole-acridine conjugate $G L 15,(B) d\left(T G_{4} T\right)$ in single-stranded and in $G$-quadruplex configurations and $(C)$ the polv $(G)$ adsorption process.

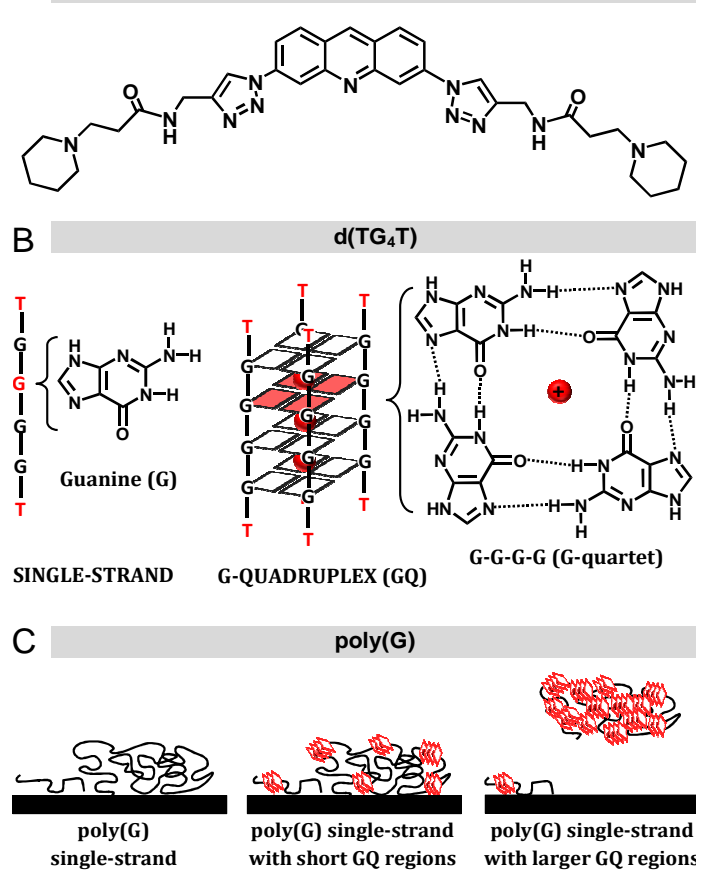

DNA-electrochemical biosensors are important tools for the detection and evaluation of small molecule specific binding to nucleic acids, ${ }^{21-25}$ due to their high sensitivity for the 
detection of small perturbations of DNA morphology. The morphological characteristics of DNA molecules in GQ configurations have been recently investigated at carbon electrodes, ${ }^{26-33}$ from the viewpoint of nanotechnology and biosensor technology applications. The characterisation of the binding process between GQ ligands and GQ regions of DNA, without any labelling, emerges as a necessary step for the development of sensitive GQ-based biosensor devices.

The triazole-acridine conjugate compound GL15 has been investigated by voltammetric techniques, providing new data concerning its interaction with duplex DNA. ${ }^{34}$

The Tetrahymena telomeric repeat sequence d(TG4T) (Scheme 1B) forms parallelstranded tetra-molecular GQs in the presence of $\mathrm{Na}+$ and $\mathrm{K}+\mathrm{ions}^{35}$ and is considered to be a simple model for biologically relevant GQs. It has also pro-vided high resolution structural data on drug-DNA interac-tions. ${ }^{36,37}$ Synthetic polynucleotides poly(dG) and poly $(\mathrm{G})$ are also widely used as models to determine the interaction of drugs with G-rich segments of DNA.

This paper reports an exhaustive qualitative analytical study on the interactions of the short-length sequence $d\left(\mathrm{TG}_{4} \mathrm{~T}\right)$ and long polyguanylic acid $(\operatorname{poly}(\mathrm{G}))$ sequence with the triazole-acridine conjugate GL15, using a novel approach, based on the combination of two powerful analytical techniques, atomic force microscopy (AFM) onto a highly oriented pyrolytic graphite (HOPG) surface, and differential pulse (DP) voltam-metry at a glassy carbon electrode (GCE). The interaction of GL15 with $\mathrm{d}\left(\mathrm{TG}_{4} \mathrm{~T}\right)$ and poly $(\mathrm{G})$ was evaluated based on changes in structure and redox behaviour, enhanced by the presence of $\mathrm{Na}^{+}$or $\mathrm{K}^{+}$ions.

\section{Materials and Methods}

\subsection{Materials and Reagents}

The 6-mer single-stranded hexadeoxyribonucleotide se-quence 5'-TGGGGT-3' $\left(\mathrm{d}\left(\mathrm{TG}_{4} \mathrm{~T}\right)\right.$ ) was synthesized on an Applied Biosystems 380B automated DNA synthesizer (USA) using reagents for oligodeoxyribonucleotides chemistry (Fluka, Germany). The $\mathrm{d}\left(\mathrm{TG}_{4} \mathrm{~T}\right)$ purity was verified by NMR and HPLC analysis. Polyguanylic acid (poly $(\mathrm{G}))$ purchased from Sigma-Aldrich was used without further purification.

The triazole-acridine conjugate GL15 $N, N^{\prime}$-((1,1'-(acridine-3,6-diyl)bis(1H-1,2,3triazole-4,1-diyl))bis(methylene))bis(2-(piperidin-1-yl)propanamide) was synthesized and purified by the previously described methods. ${ }^{19}$

The supporting electrolyte solution was $0.1 \mathrm{M}$ phosphate buffer $\mathrm{pH}=7.0$, containing $\mathrm{Na}^{+}$ ions $\left(0.2 \mathrm{M} \mathrm{NaH}_{2} \mathrm{PO}_{4}+0.2 \mathrm{M} \mathrm{Na}_{2} \mathrm{HPO}_{4}\right)$ or $\mathrm{K}^{+}$ions $\left(0.2 \mathrm{M} \mathrm{KH}_{2} \mathrm{PO}_{4}+0.2 \mathrm{M} \mathrm{K}_{2} \mathrm{HPO}_{4}\right)$, prepared using analytical grade reagents and purified water from a Millipore Milli-Q system, with conductivity $<0.1 \mu \mathrm{S} \mathrm{cm}^{-1}$.

The $\mathrm{d}\left(\mathrm{TG}_{4} \mathrm{~T}\right)$ control and $\mathrm{GL} 15-\mathrm{d}\left(\mathrm{TG}_{4} \mathrm{~T}\right)$ stock solutions were prepared using $3.0 \mu \mathrm{M}$ $\mathrm{d}\left(\mathrm{TG}_{4} \mathrm{~T}\right)$ incubated in the absence/presence of $4.0 \mu \mathrm{M}$ GL15, in supporting electrolyte.

The poly(G) control and GL15-poly(G) stock solutions were prepared using $100 \mu \mathrm{g} \mathrm{mL}$ poly(G) incubated in the absence/presence of $4.0 \mu \mathrm{M}$ GL15 in supporting electrolyte.

All experiments were done at room temperature $\left(25 \pm 1{ }^{\circ} \mathrm{C}\right)$.

\subsection{Synthetic chemistry}


To a suspension of $N$-(prop-2-yn-1-yl)-3-(piperidin-1-yl)propanamide $(0.31 \mathrm{~g}, 1.60$ $\mathrm{mmol})$ and 3,6-diazidoacridine $(0.20 \mathrm{~g}, 0.77 \mathrm{mmol})$ in tBuOH $(2 \mathrm{~mL})$, a solution of (+)sodium L-ascorbate $(0.076 \mathrm{~g}, 0.38 \mathrm{mmol})$ and copper(II) sulfate pentahydrate $(0.019 \mathrm{~g}$, $0.077 \mathrm{mmol})$ in $\mathrm{H} 2 \mathrm{O}(2 \mathrm{~mL})$ was added in one portion. The heterogeneous mixture was treated according to the general procedure to afford a brown solid $(0.047 \mathrm{~g}, 28 \%) .{ }^{19}$

\subsection{Atomic force microscopy}

AFM was performed in the acoustic AC mode, with a Pico-Scan controller and a CS AFM S scanner with a scan range of $6 \mu \mathrm{m}$ in $\mathrm{x}-\mathrm{y}$ and $2 \mu \mathrm{m}$ in $\mathrm{z}$ (Agilent Technologies, USA). App-Nano type FORT of $225 \mu \mathrm{m}$ length, $3.0 \mathrm{~N} \mathrm{~m}^{-1}$ spring constants and 47-76 $\mathrm{kHz}$ resonant frequencies in air (Applied NanoS-tructures, Inc., USA) were used. All AFM images were topographical and were taken with 512 samples/line x 512 lines and scan rates of $0.8-2.5$ lines $\mathrm{s}^{-1}$.

HOPG, grade ZYB of $15 \times 15 \times 2 \mathrm{~mm}^{3}$ dimensions (Advanced Ceramics Co., USA) was used as a substrate in the AFM study, because is atomically flat with less than $0.06 \mathrm{~nm}$ of root-mean-square (r.m.s.) roughness for a $1000 \mathrm{x} 1000 \mathrm{~nm}^{2}$ surface area. The GCE used for the voltammetric characterisation is much rougher, with $2.10 \mathrm{~nm}$ r.m.s. roughness for the same surface area, therefore unsuitable for AFM surface characterisation. The electrochemical experiments showed similar redox behaviour using GCE and HOPG.

For each incubation time investigated by AFM, the d(TG $\left.\mathrm{TG}_{4} \mathrm{~T}\right)$ control and GL15-d(TG $\left.\mathrm{TG}_{4} \mathrm{~T}\right)$ stock solutions were diluted in buffer to $0.3 \mu \mathrm{M} \mathrm{d}\left(\mathrm{TG}_{4} \mathrm{~T}\right)$ without/with $0.4 \mu \mathrm{M}$ GL15, and the poly $(\mathrm{G})$ control and GL15-poly $(\mathrm{G})$ stock solutions were diluted in buffer to $5.0 \mu \mathrm{g}$ $\mathrm{mL}^{-1} \operatorname{poly}(\mathrm{G})$ without/with $0.2 \mu \mathrm{M}$ GL15, in order to maintain the same $\mathrm{d}\left(\mathrm{TG}_{4} \mathrm{~T}\right)$ : GL15 and poly $(\mathrm{G})$ :GL15 ratios in the AFM and voltammetric experiments.

The HOPG surfaces were modified by spontaneous adsorption of $\mathrm{d}\left(\mathrm{TG}_{4} \mathrm{~T}\right)$ control, GL15-d(TG $\left.\mathrm{TG}_{4} \mathrm{~T}\right)$, poly $(\mathrm{G})$ control and GL15-poly(G), after depositing $100 \mu \mathrm{L}$ of each solution onto the freshly cleaved HOPG, over a period of $3 \mathrm{~min}$. The solution excess was gently cleaned with Milli-Q water, and the HOPG with the adsorbed molecules was then dried in a sterile atmosphere and imaged by AFM in air. This procedure provided reproducible qualitative analytical results when compared with AFM in solution, when the adsorption of molecules continued to occur during the AFM experiments and difficult the surface coverage comparison.

\subsection{Voltammetric experiments}

Voltammetry was carried out using a $\mu$ Autolab Type II potentiostat running with GPES 4.9 software (Metrohm-Autolab, The Netherlands). DP voltammetry conditions were: pulse amplitude $50 \mathrm{mV}$, pulse width $70 \mathrm{~ms}$ and scan rate $5 \mathrm{mV} \mathrm{s}^{-1}$. Measurements were carried out using a GCE working $(d=1 \mathrm{~mm})$, a Pt wire counter and an $\mathrm{Ag} / \mathrm{AgCl}(3 \mathrm{M}$ $\mathrm{KCl}$ ) reference electrodes, in a one-compartment $2 \mathrm{~mL}$ electrochemical cell.

Before every electrochemical assay, the GCE was polished using diamond spray (particle size $1 \mu \mathrm{m}$ ), rinsed with Milli-Q water, placed in buffer supporting electrolyte, and various DP voltammograms were recorded until a steady state baseline voltammogram was obtained.

For each incubation time investigated, DP voltammograms of $\mathrm{d}\left(\mathrm{TG}_{4} \mathrm{~T}\right)$ control, GL15$\mathrm{d}\left(\mathrm{TG}_{4} \mathrm{~T}\right)$, poly $(\mathrm{G})$ control and GL15-poly $(\mathrm{G})$ stock solutions, were obtained. The GCE was always cleaned by polishing between measurements, to avoid misleading results 
from the $\mathrm{d}\left(\mathrm{TG}_{4} \mathrm{~T}\right)$, poly $(\mathrm{G})$ or GL15 adsorption. The DP voltammograms were baseline corrected using the moving average with a step window of $2 \mathrm{mV}$ included in the GPES (version 4.9) software.

\section{Results}

\subsection{Interaction of $d\left(\mathrm{TG}_{4} \mathrm{~T}\right)$ with $\mathrm{GL} 15$}

The $d\left(\mathrm{TG}_{4} \mathrm{~T}\right)$ contains one block of four contiguous guanine residues which can form a parallel-stranded tetra-molecular GQ, stabilized by $\pi-\pi$ interactions between the Gquartets and to some extent by the thymine residues present at the 5' and 3' ends (Scheme 1B).

The mechanism of interaction between GL15 and $\mathrm{d}\left(\mathrm{TG}_{4} \mathrm{~T}\right)$ to form a GL15-d(TG $\left.\mathrm{TH}_{4} \mathrm{~T}\right)$ complex and the influence of GL15 on GQ formation and stabilisation have been investigated. For control and a correct evaluation of structural changes in $\mathrm{d}\left(\mathrm{TG}_{4} \mathrm{~T}\right)$ after interaction with GL15, the GL15 and $\mathrm{d}\left(\mathrm{TG}_{4} \mathrm{~T}\right)$ control adsorption patterns and redox behaviour were also studied.

\subsubsection{AFM characterisation}

The GL15 and d(TG $\left.\mathrm{TG}_{4} \mathrm{~T}\right)$ controls and GL15-d(TG $\left.\mathrm{TG}_{4} \mathrm{~T}\right)$ films were obtained by spontaneous adsorption onto HOPG, as de-scribed in Section 2.3.

Figure 1 - AFM images of GL15 control at: (A) $0.4 \mu M$ and (B) $4.0 \mu M$.

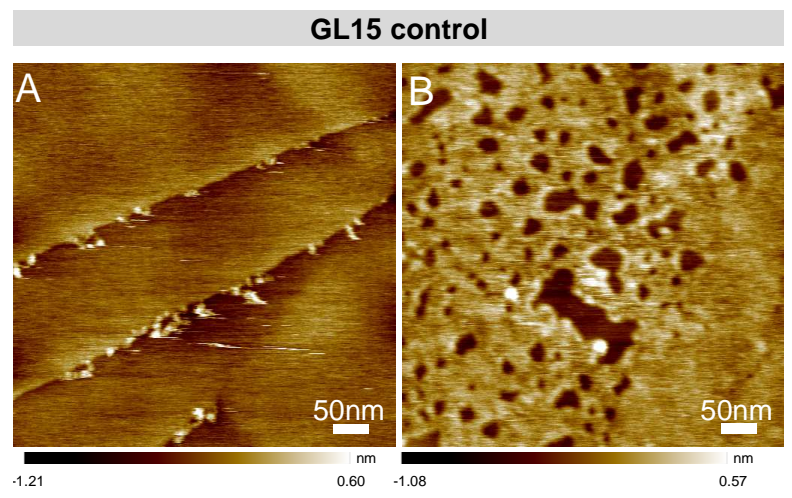

GL15 and d(TG $\mathbf{4}$ T) control. AFM images of the GL15 control, for $0.2 \mu \mathrm{M}$ and $0.4 \mu \mathrm{M}$ (Fig. 1A), the concentrations used in the AFM study, and for $4.0 \mu \mathrm{M}$ (Fig. 1B), the concen-tration used in the voltammetric study, showed different ad-sorption coverages. AFM images of $0.2 \mu \mathrm{M}$ and $0.4 \mu \mathrm{M}$ GL15 control showed very weak adsorption onto HOPG, suggesting negligible non-specific adsorption of GL15, whereas AFM images of $4.0 \mu \mathrm{M}$ GL15 control showed almost complete HOPG coverage by a smooth film, $0.70 \pm$ $0.05 \mathrm{~nm}$ height, corresponding to the adsorption of a self-assembled GL15 monolayer, with the acridine moieties lying flat on the surface.

The $\mathrm{d}\left(\mathrm{TG}_{4} \mathrm{~T}\right)$ control adsorption pattern was obtained in $0.3 \mu \mathrm{M} \mathrm{d}\left(\mathrm{TG}_{4} \mathrm{~T}\right)$ in the presence of $\mathrm{Na}^{+}$or $\mathrm{K}^{+}$ions, at different times. AFM images of the $\mathrm{d}\left(\mathrm{TG}_{4} \mathrm{~T}\right)$ control in freshly prepared solutions (Figs. $2 \mathrm{~A}$ in $\mathrm{Na}^{+}$and $2 \mathrm{~B}$ in $\mathrm{K}^{+}$ions) showed only the $\mathrm{d}\left(\mathrm{TG}_{4} \mathrm{~T}\right.$ ) single- 
strand adsorption, detected as $0.87 \pm 0.1 \mathrm{~nm}$ height randomly oriented polymeric structures ( $\boldsymbol{r} \boldsymbol{P}$ - random polymer).

On increasing the $\mathrm{d}\left(\mathrm{TG}_{4} \mathrm{~T}\right.$ ) control time from 0 to 42 days (Figs. $3 \mathrm{~A}, \mathrm{~B}$ in $\mathrm{Na}^{+}$and $3 \mathrm{C}$ in $\mathrm{K}^{+}$ions), the $\mathrm{d}\left(\mathrm{TG}_{4} \mathrm{~T}\right)$ single-strands started to self-assemble into short tetra-molecular $\mathrm{d}\left(\mathrm{TG}_{4} \mathrm{~T}\right)-\mathrm{GQ}$ complexes (Scheme 1B). The AFM images showed: (i) the decrease and disappearance of the $\boldsymbol{r} \boldsymbol{P}$ structures, due to a decrease in the number of $\mathrm{d}\left(\mathrm{TG}_{4} \mathrm{~T}\right)$ single strands, (ii) the occurrence and the increase of a number of small $2.05 \pm 0.5 \mathrm{~nm}$ height spherical aggregates $(\boldsymbol{A}$ - aggregates $)$, due to the adsorption of $\mathrm{d}\left(\mathrm{TG}_{4} \mathrm{~T}\right)-\mathrm{GQs}$, and (iii) in $\mathrm{Na}^{+}$containing solutions, the occurrence of a few $1.52 \pm 0.4 \mathrm{~nm}$ height polymeric nanostructures ( $\boldsymbol{N}$ - nanostructures).

The presence of $\mathrm{K}^{+}$ions has stabilized and accelerated GQ formation, and after 42 days incubation in $\mathrm{K}^{+}$ions only $\mathrm{d}\left(\mathrm{TG}_{4} \mathrm{~T}\right)$-GQ complexes are observed (Fig. 3C), when compared with $\mathrm{Na}^{+}$ions, where $\mathrm{d}\left(\mathrm{TG}_{4} \mathrm{~T}\right)$ single-stranded species are still present (Fig. 3A).

GL15-d(TG $\mathbf{T} \mathbf{T})$ interaction. The GL15-d $\left(\mathrm{TG}_{4} \mathrm{~T}\right)$ interaction was investigated using a solution of $3.0 \mu \mathrm{M} \mathrm{d}\left(\mathrm{TG}_{4} \mathrm{~T}\right)$ incubated with $0.4 \mu \mathrm{M}$ GL15 for a range of incubation times, in the presence of $\mathrm{Na}^{+}$or $\mathrm{K}^{+}$ions. This procedure led to the co-adsorption of GL15$\mathrm{d}\left(\mathrm{TG}_{4} \mathrm{~T}\right)$ complexes together with free $\mathrm{d}\left(\mathrm{TG}_{4} \mathrm{~T}\right)$ and GL15 molecules.

Figure 2 - Freshly prepared solutions. AFM images: $(A, B) d(T G 4 T)$ control and $(C, D)$ GL15$d\left(T G_{4} T\right)$, in the presence of $(A, C) N^{+}$and $(B, D) K^{+}$ions. DP voltammograms baseline corrected: (-) $d\left(T G_{4} T\right)$ control, (--) GL15 control and (-) GL15-d(TG $T$ ), in the presence of (E) $\mathrm{Na}^{+}$and $(F) \mathrm{K}^{+}$ions.

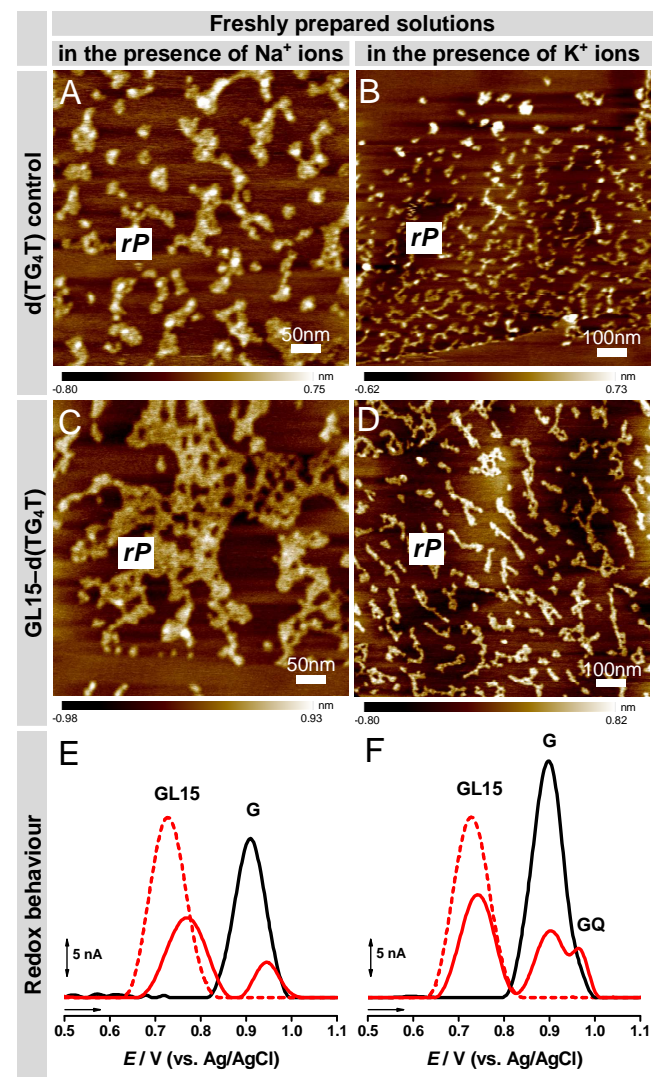


AFM images of GL15-d( $\left.\mathrm{TG}_{4} \mathrm{~T}\right)$ freshly prepared solutions showed only $\boldsymbol{r} \boldsymbol{P}$ structures, $0.92 \pm 0.10 \mathrm{~nm}$ height in the presence of $\mathrm{Na}^{+}$ions (Fig. 2C) and $0.89 \pm 0.1 \mathrm{~nm}$ height in the presence of $\mathrm{K}^{+}$ions (Fig. 2D), due to the adsorption of GL15-d(TG ${ }_{4} \mathrm{~T}$ ) and $\mathrm{d}\left(\mathrm{TG}_{4} \mathrm{~T}\right.$ ) single-stranded species, similar to what was previously observed for $\mathrm{d}\left(\mathrm{TG}_{4} \mathrm{~T}\right)$ in freshly prepared solutions (Figs. 2A with $\mathrm{Na}^{+}$and $2 \mathrm{~B}$ with $\mathrm{K}^{+}$ions).

Increasing the GL15-d( $\mathrm{TG}_{4} \mathrm{~T}$ ) incubation time from 0 to 42 days (Figs. 3D in $\mathrm{Na}^{+}$and $3 \mathrm{E}$ in $\mathrm{K}^{+}$ions) results in the $\mathrm{d}\left(\mathrm{TG}_{4} \mathrm{~T}\right)$ single strands self-assembling into $\mathrm{d}\left(\mathrm{TG}_{4} \mathrm{~T}\right)-\mathrm{GQ}$ s both with and without bound GL15. The AFM images showed: (i) the decrease and the disappearance of the $\boldsymbol{r} \boldsymbol{P}$ structures, due to a decrease in the number of available $\mathrm{d}\left(\mathrm{TG}_{4} \mathrm{~T}\right)$ single strands, (ii) the occurrence and increase of the $2.32 \pm 0.6 \mathrm{~nm}$ height $\boldsymbol{A}$ aggregates corresponding to GQ adsorption and (iii) the occurrence of $1.52 \pm 0.4 \mathrm{~nm}$ height $N$ nanostructures in the presence of $\mathrm{Na}^{+}$ions.

Figure 3 - Incubation for 42 days. AFM images: $(A, B, C) d\left(T G_{4} T\right)$ control and $(D, E)$ GL15$d\left(T G_{4} T\right)$, in the presence of $(A, B, D) N^{+}$and $(C, E) K^{+}$ions. DP voltammograms baseline corrected: (-) $d\left(T G_{4} T\right)$ control, ("-) GL15 control and (-) GL15-d(TG $T$ ), in the presence of (G) $\mathrm{Na}^{+}$and $(F) \mathrm{K}^{+}$ions.

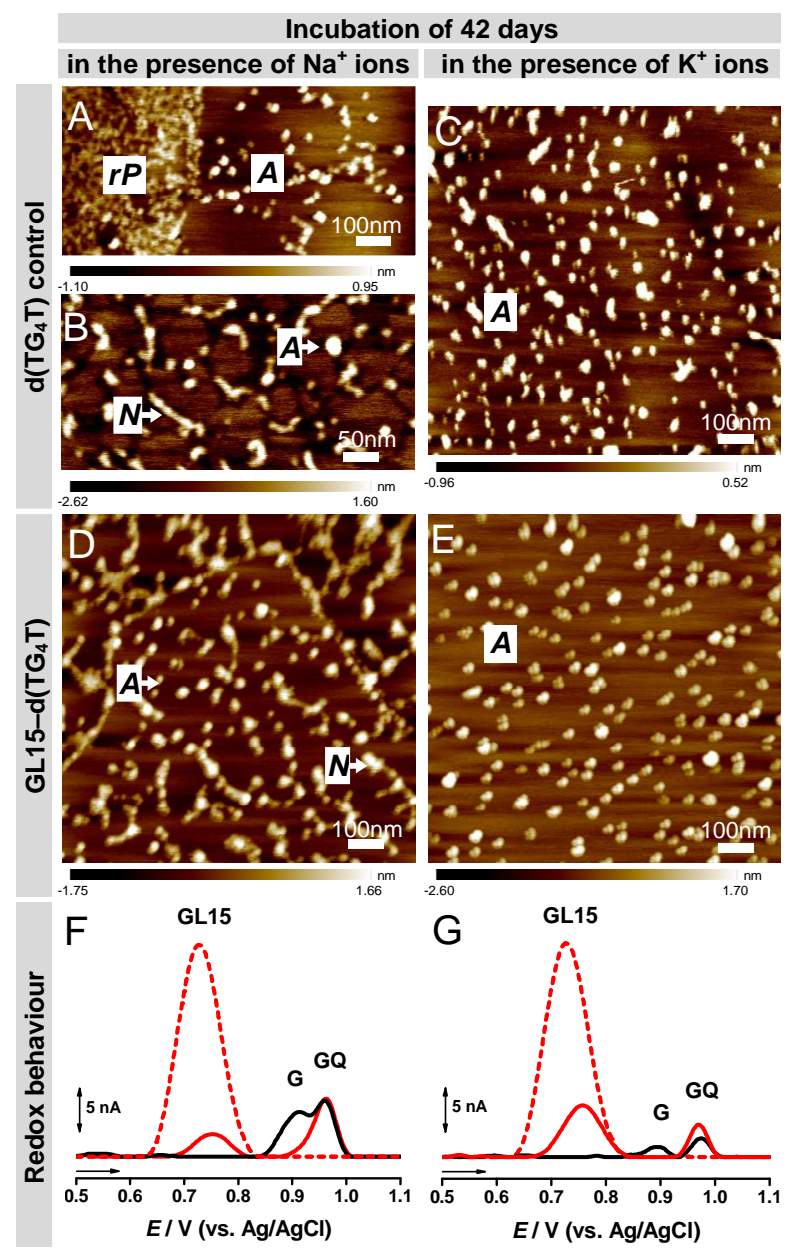

The GQ height measured in AFM images is similar to the $~ 2.6 \mathrm{~nm}$ diameter measured by X-ray crystallography. ${ }^{35}$ The GQ structures formed by GL15-d(TG $\left.\mathrm{TG}_{4} \mathrm{~T}\right)$ and $\mathrm{d}\left(\mathrm{TG}_{4} \mathrm{~T}\right)$ 
interacted and adsorbed less on the hydrophobic HOPG, because they have the guanine bases buried in the interior of the structures, protected by the sugar-phosphate backbones, when compared with the single-stranded unfolded structures with bases more exposed and freer to undergo hydrophobic interactions with the carbon surface. ${ }^{38}$

After 42 days incubation of GL15-d( $\left.\mathrm{TG}_{4} \mathrm{~T}\right)$ in the presence of $\mathrm{Na}^{+}$ions, no single strands were observed (Fig. 3D), when compared with $\mathrm{d}\left(\mathrm{TG}_{4} \mathrm{~T}\right)$ control (Fig. 3A), demonstrating that GL15 binding to $\mathrm{d}\left(\mathrm{TG}_{4} \mathrm{~T}\right)$ accelerated the formation of GQ-ligand complexes.

The formation of d $\left(\mathrm{TG}_{4} \mathrm{~T}\right)$ higher-order $\boldsymbol{N}$ nanostructures was observed only in solutions containing $\mathrm{Na}^{+}$ions for long incubation times, independent of the presence of GL15 in solution. The presence of $\mathrm{K}^{+}$ions promoted the rapid formation of stable and perfectly aligned tetra-molecular GQs, and consequently higher-order nanostructures did not form.

\subsubsection{Voltammetric characterisation}

GL15 and $\mathbf{d}\left(\mathbf{T G}_{\mathbf{4}} \mathbf{T}\right)$ control. DP voltammograms in $4.0 \mu \mathrm{M}$ GL15 control showed the occurrence of one GL15 oxidation peak, at $E_{\mathrm{pa}}=+0.77 \mathrm{~V}$ (Figs. 2E, F"* and 3F, G"**). The $\mathrm{d}\left(\mathrm{TG}_{4} \mathrm{~T}\right)$ control redox behaviour was investigated in solutions of $3.0 \mu \mathrm{M} \mathrm{d}\left(\mathrm{TG}_{4} \mathrm{~T}\right)$ in the presence of $\mathrm{Na}+$ or $\mathrm{K}+$ ions, at different times. DP voltammograms of $\mathrm{d}\left(\mathrm{TG}_{4} \mathrm{~T}\right)$ control in freshly prepared solutions (Figs. $2 \mathrm{E}-$ in $\mathrm{Na}+$ and $2 \mathrm{~F}-$ in $\mathrm{K}+$ ions), showed the occurrence of only one $\mathrm{G}$ oxidation peak, due to the oxidation of the guanine residues in the $\mathrm{d}\left(\mathrm{TG}_{4} \mathrm{~T}\right)$ single strands (Scheme 1B-left), at the $\mathrm{C} 8-\mathrm{H}$ position, in a two-step mechanism each involving two electrons and two proton transfers. ${ }^{39}$

On increasing the $\mathrm{d}\left(\mathrm{TG}_{4} \mathrm{~T}\right)$ control time from 0 to 42 days (Figs. $3 \mathrm{~F}-$ in $\mathrm{Na}^{+}$and $3 \mathrm{G}-$ in $\mathrm{K}^{+}$ions), the $\mathrm{d}\left(\mathrm{TG}_{4} \mathrm{~T}\right)$ single strands started to self-assemble into $\mathrm{d}\left(\mathrm{TG}_{4} \mathrm{~T}\right)$-GQs (Scheme 1B-right). ${ }^{39}$ The DP voltammograms showed: (i) a decrease in the guanine $(\mathrm{G})$ oxidation peak current and (ii) occurrence and increase of the GQ oxidation peak current, due to the oxidation of the guanine residues in the $\mathrm{d}\left(\mathrm{TG}_{4} \mathrm{~T}\right)$-GQs that were formed.

The $\mathrm{G}$ oxidation peak current decrease is due to a decrease in the number of guanine residues in the $\mathrm{d}\left(\mathrm{TG}_{4} \mathrm{~T}\right)$ single strands, and the GQ oxidation peak current increase is due to an increase in the overall number of GQs. The GQ oxidation peak potential is higher relative to the $\mathrm{G}$ oxidation peak potential, due to the greater distance for the electron transfer from the interior of the rigid GQs to the GCE surface, than from the more flexible $d\left(\mathrm{TG}_{4} \mathrm{~T}\right)$ single strands. The oxidation of thymine residues in $\mathrm{d}\left(\mathrm{TG}_{4} \mathrm{~T}\right)$ is not detected by DP voltammetry, because it occurs at a much greater positive potential, near the potential of oxygen evolution. ${ }^{20}$

GL15-d(TG $\left.\mathbf{T G}_{4} \mathbf{T}\right)$ interaction. The GL15-d $\left(\mathrm{TG}_{4} \mathrm{~T}\right)$ interaction was investigated in solutions of $3.0 \mu \mathrm{M} \mathrm{d}\left(\mathrm{TG}_{4} \mathrm{~T}\right)$ incubated with $4.0 \mu \mathrm{M}$ GL15, in the presence of $\mathrm{Na}^{+}$or $\mathrm{K}^{+}$ ions, for a range of incubation times. The GL15, G and GQ oxidation peaks of the GL15$\mathrm{d}\left(\mathrm{TG}_{4} \mathrm{~T}\right)$ complex were compared with the oxidation peaks of $\mathrm{d}\left(\mathrm{TG}_{4} \mathrm{~T}\right)$ and GL15 controls.

(a) Freshly prepared solutions

GL15-d $\left(\mathrm{TG}_{4} \mathrm{~T}\right)-\mathrm{GQs}$ formation in the presence of $\mathrm{Na}^{+}$ions was a slow process. DP voltammograms of GL15-d $\left(\mathrm{TG}_{4} \mathrm{~T}\right)$ showed the occurrence of two oxidation peaks (Fig. 2E-): (i) the GL15 oxidation peak, at $E_{\mathrm{pa}}=+0.77 \mathrm{~V}$, and (ii) the G oxidation peak, at 
$E_{\mathrm{pa}}=+0.95 \mathrm{~V}$, corresponding to the $\mathrm{d}\left(\mathrm{TG}_{4} \mathrm{~T}\right)$ single strands, in agreement with the adsorption of solely single-stranded GL15-d $\left(\mathrm{TG}_{4} \mathrm{~T}\right)$ and $\mathrm{d}\left(\mathrm{TG}_{4} \mathrm{~T}\right)$ molecules observed in the AFM (Fig. 2C).

GL15-d(TG $\left.\mathrm{TG}_{4} \mathrm{~T}\right)-\mathrm{GQs}$ formation in the presence of $\mathrm{K}^{+}$ions was very rapid. DP voltammograms of GL15-d $\left(\mathrm{TG}_{4} \mathrm{~T}\right)$ immediately showed the occurrence of three oxidation peaks (Fig. 2F-): (i) the GL15 oxidation peak, at $E_{\mathrm{pa}}=+0.74 \mathrm{~V}$, (ii) the $\mathrm{G}$ oxidation peak of the $\mathrm{d}\left(\mathrm{TG}_{4} \mathrm{~T}\right)$ single strands, at $E_{\mathrm{pa}}=+0.90 \mathrm{~V}$, and (iii) the GQ oxidation peak of the d $\left(\mathrm{TG}_{4} \mathrm{~T}\right)-\mathrm{GQs}$, at $E_{\mathrm{pa}}=+0.97 \mathrm{~V}$.

Figure 4 - DP voltammograms baseline corrected for $G L 15-d\left(T G_{4} T\right)$, with different incubation times in the presence: (A) $\mathrm{Na}^{+}$and (B) $\mathrm{K}^{+}$ions.
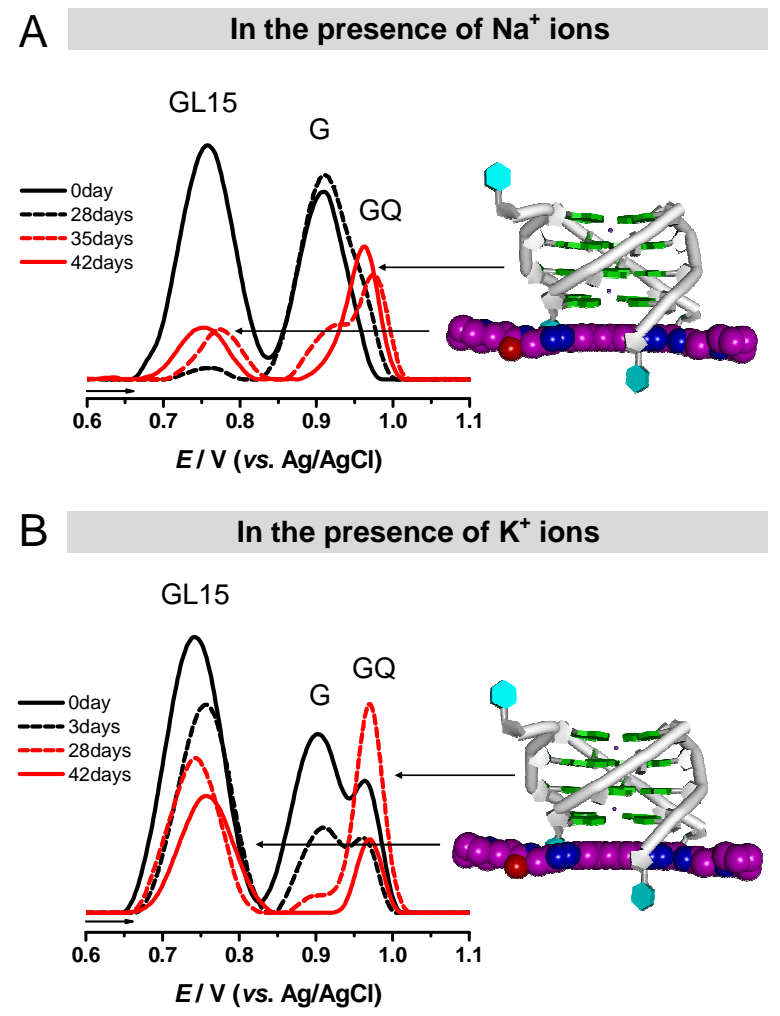

DP voltammetry of $\mathrm{d}\left(\mathrm{TG}_{4} \mathrm{~T}\right)^{39}$ and kinetic studies by absorbance spectroscopy which monitored association and dissociation of tetra-molecular GQs formed by oligonucleotides containing more than four contiguous guanine residues, ${ }^{40}$ also showed more rapid association in the presence of $\mathrm{K}^{+}$ions.

The decrease of the GL15 oxidation peak current of GL15-d(TG $\mathrm{TG}_{4}$ ) (Fig. 2E, F-), when compared with GL15 control (Fig. 2E, F-*), is due to GL15 binding to d(TG $\mathrm{TH}_{4}$ ). The decrease of the $\mathrm{G}$ oxidation peak current of $\mathrm{GL} 15-\mathrm{d}\left(\mathrm{TG}_{4} \mathrm{~T}\right)$ (Fig. 2E, F-) and the occurrence of the GQ oxidation peak in $\mathrm{K}+$ ions (Fig. 2F-), when compared with $\mathrm{d}\left(\mathrm{TG}_{4} \mathrm{~T}\right)$ control, which showed only one large $\mathrm{G}$ oxidation peak (Fig. 2E, F-), further demonstrated that GL15 binding to $\mathrm{d}\left(\mathrm{TG}_{4} \mathrm{~T}\right)$ promotes GQ formation.

(b) Increasing incubation times

The GL15-d(TG $\left.\mathrm{TG}_{4}\right)$ incubation time dependence is shown in Fig. 4. 
On increasing GL15-d( $\left.\mathrm{TG}_{4} \mathrm{~T}\right)$ incubation time in the presence of $\mathrm{Na}^{+}$ions from 0 to 42 days (Fig. 4A), the DP voltammograms showed: (i) a significant decrease in the GL15 oxidation peak current, due to GL15 binding to $\mathrm{d}\left(\mathrm{TG}_{4} \mathrm{~T}\right)$ and con-sequent decrease in the number of free GL15 molecules, (ii) a decrease in the G oxidation peak current due to a decrease in the number of $\mathrm{d}\left(\mathrm{TG}_{4} \mathrm{~T}\right)$ single strands, and (iii) the GQ oxidation peak occurrence (Fig. 4A-- 28 days incubation) and increase (Fig. 4A=- 35 days and -42 days incubation), due to the formation and stabilization of $\mathrm{d}\left(\mathrm{TG}_{4} \mathrm{~T}\right)$-GQ complexes (Fig. 4A-left).

On increasing the GL15-d( $\left.\mathrm{TG}_{4} \mathrm{~T}\right)$ incubation time in the presence of $\mathrm{K}^{+}$ions, from 0 to 42 days (Fig. 4B), the DP voltammograms showed: (i) a decrease in the GL15 oxidation peak current (ii) a decrease in the $G$ oxidation peak current and (iii) a progressive increase of the GQ oxidation peak cur-rent up to 28 days incubation (Fig. 4B-- 28 days incubation), due to the formation and stabilization of $\mathrm{d}\left(\mathrm{TG}_{4} \mathrm{~T}\right)-\mathrm{GQs}$ (Fig. 4B-left), followed by a decrease in the GQ oxidation peak current for 35 and 42 days incubation (Fig. 4B-).

The decrease in the GQ oxidation peak current for long incubation times occurred only with GL15-d( $\left.\mathrm{TG}_{4} \mathrm{~T}\right)$ in the presence of $\mathrm{K}^{+}$ions (Fig. 4B- 42 days incubation), and was not observed in the presence of $\mathrm{Na}^{+}$ions (Fig. 4A- 42 days incubation), nor in the $\mathrm{d}\left(\mathrm{TG}_{4} \mathrm{~T}\right)$ control with $\mathrm{Na}^{+}$or $\mathrm{K}^{+}$ions. This demonstrated that GL15 binding to $\mathrm{d}\left(\mathrm{TG}_{4} \mathrm{~T}\right)$ GQs in $\mathrm{K}^{+}$ions confers greater structural stability to the very rigid and stable $\mathrm{d}\left(\mathrm{TG}_{4} \mathrm{~T}\right)$ GQs, the transition of electrons from the interior guanines being more difficult. This is in agreement with the AFM results which showed rapid formation of solely GQ structures in solutions containing $\mathrm{K}^{+}$ions (Fig. 3E).

The presence of GL15 strongly stabilized and accelerated $\mathrm{d}\left(\mathrm{TG}_{4} \mathrm{~T}\right)$-GQ formation, and after 42 days incubation almost all GL15 was bound only to d(TG 4 T)-GQs. Indeed, after 42 days incubation, DP voltammograms of GL15-d( $\left.\mathrm{TG}_{4} \mathrm{~T}\right)$ showed small GL15 oxidation peak shoulders and only the GQ oxidation peak was present (Figs. $3 \mathrm{~F}-$ in $\mathrm{Na}^{+}$and $3 \mathrm{G}-$ in $\mathrm{K}^{+}$ions), when compared with the $\mathrm{d}\left(\mathrm{TG}_{4} \mathrm{~T}\right)$ control which still showed the $\mathrm{G}$ oxidation peak of $\mathrm{d}\left(\mathrm{TG}_{4} \mathrm{~T}\right.$ ) single strands (Fig. 3F, G-).

In addition, the $\mathrm{G}$ oxidation peak of $\mathrm{GL} 15-\mathrm{d}\left(\mathrm{TG}_{4} \mathrm{~T}\right)$ was always smaller compared to the G oxidation peak of the $d\left(\mathrm{TG}_{4} \mathrm{~T}\right)$ control, due to the reduced number of $d\left(\mathrm{TG}_{4} \mathrm{~T}\right)$ single strands in the presence of GL15. The AFM results confirmed that upon increasing the incubation time, GL15-d( $\left.\mathrm{TG}_{4} \mathrm{~T}\right)$ complex self-assembled into short GQs (Fig. 3D, E). The GL15 acridine chromophore prefers to bind on the terminal G-quartet stacks of the $\mathrm{d}\left(\mathrm{TG}_{4} \mathrm{~T}\right)-\mathrm{GQs}$. This is quite distinct from intercalation into DNA duplex; even though the GL15 extended electron aromatic ring system enables it to form strong $\pi$ - $\pi$ stacking interactions with the guanine bases, as observed with a number of small molecule-GQ complexes (see for example ${ }^{41-43}$ ) the triazole-acridine compounds as a class do not show significant duplex DNA affinity ${ }^{19}$, in contrast to many other substituted acridines.

\subsection{Interaction of $\operatorname{poly}(G)$ with GL15}

\subsubsection{AFM characterisation}

The deposited films of poly $(\mathrm{G})$ control and GL15-poly $(\mathrm{G})$ were obtained by spontaneous adsorption onto $\mathrm{HOPG}$, using solutions of $5.0 \mu \mathrm{g} \mathrm{mL}^{-1}$ poly $(\mathrm{G})$ incubated in the presence and absence of $0.2 \mu \mathrm{M}$ GL15, with $\mathrm{Na}^{+}$or $\mathrm{K}^{+}$ions, for different time periods. 
Poly $(\mathrm{G})$ control. AFM images of the poly $(\mathrm{G})$ control in freshly prepared solutions (Figs. $5 \mathrm{~A}$ in $\mathrm{Na}^{+}$and $5 \mathrm{~B}$ in $\mathrm{K}^{+}$ions) showed the adsorption of solely poly $(\mathrm{G})$ single-strands (Scheme 1C-left), detected in the AFM images as $0.7 \pm 0.1 \mathrm{~nm}$ height $\boldsymbol{r P}$ structures.

Figure 5 - Freshly prepared solutions. AFM images: $(A, B)$ poly $(G)$ control and $(C, D) G L 15$ poly $(G)$, in the presence of $(A, C) \mathrm{Na}^{+}$and $(B, D) K^{+}$ions. DP voltammograms baseline corrected: (-) poly $(G)$ control, (-") GL15 control and (-) GL15-poly $(G)$, in the presence of $(E)$ $\mathrm{Na}^{+}$and $(\mathrm{F}) \mathrm{K}^{+}$ions.

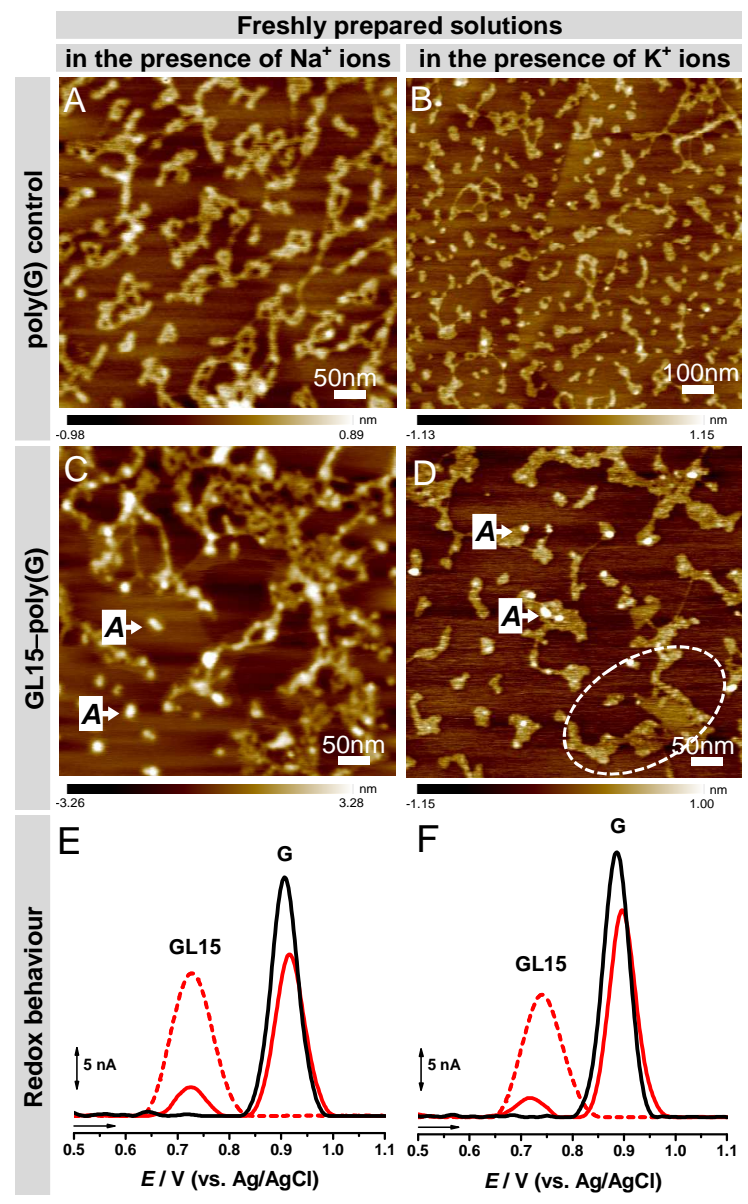

AFM images of poly $(G)$ control with increasing times, from 0 to 28 days, showed: (i) a decrease in $\boldsymbol{r P}$ structures due to a decrease in the number of poly $(\mathrm{G})$ single strands, (ii) the occurrence and increase in the number of $2.2 \pm 0.3 \mathrm{~nm}$ height A spherical aggregates, due to the formation of short GQ regions along the poly $(\mathrm{G})$ single strands, and (iii) for large incubation times (28 days incubation), the formation of compact poly $(\mathrm{G})$ aggregated morphologies in $\mathrm{Na}^{+}$ions (Fig. 6A) and a very low pattern of adsorption in $\mathrm{K}^{+}$ ions solutions (Fig. 6B), due to the formation of large poly $(\mathrm{G})-\mathrm{GQ}$ assemblies. ${ }^{32}$ The short poly $(\mathrm{G})-\mathrm{GQ}$ regions formed after short incubation times were dragged down to the surface by the larger poly $(\mathrm{G})$ single-strand adsorption onto HOPG (Scheme 1C-middle), while larger poly $(\mathrm{G})-\mathrm{GQ}$ assemblies, formed after long incubation times, stayed in solution and had very low adsorption (Scheme 1C-right). 
Figure 6 - Incubation for 28 days. AFM images: $(A, B)$ poly $(G)$ control and $(C, D)$ GL15poly $(G)$, in the presence of $(A, C) \mathrm{Na}^{+}$and $(B, D) K^{+}$ions. DP voltammograms baseline corrected: (-) poly $(G)$ control, (-") GL15 control and (-) GL15-poly $(G)$, in the presence of $(E)$ $\mathrm{Na}^{+}$and $(\mathrm{F}) \mathrm{K}^{+}$ions.

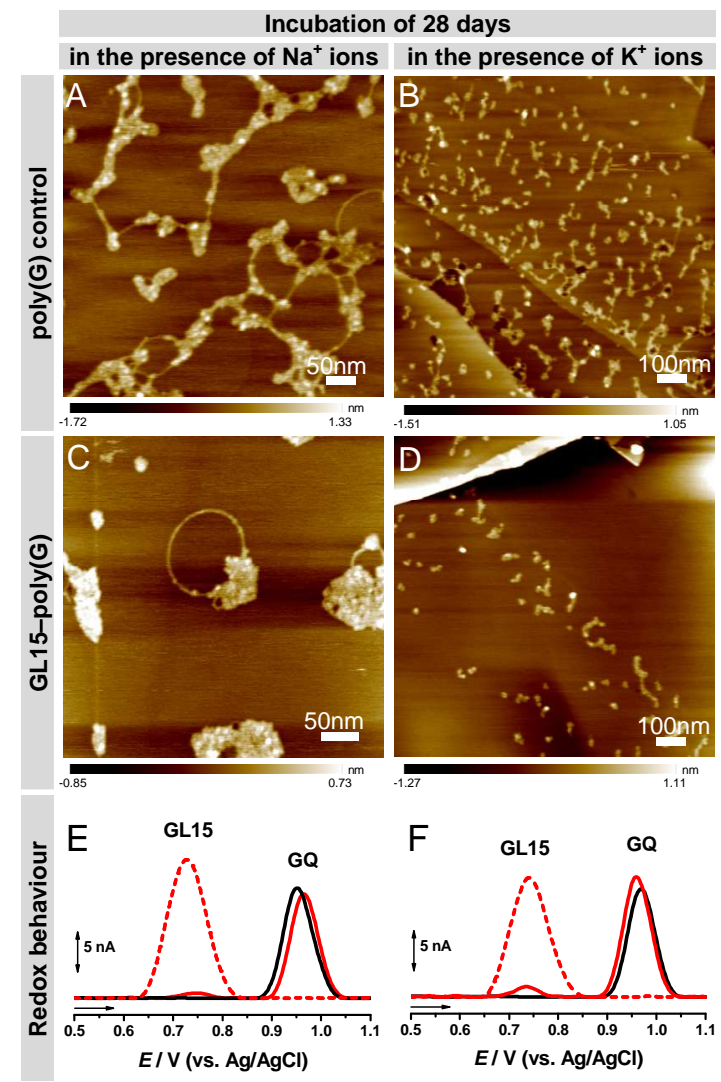

GL15-poly(G) interaction. AFM images of GL15-poly $(G)$ in freshly prepared solution (Figs. 5C in $\mathrm{Na}^{+}$and $5 \mathrm{D}$ in $\mathrm{K}^{+}$), showed two adsorption morphologies: (i) $0.7 \pm 0.1 \mathrm{~nm}$ height $\boldsymbol{r P}$ structures due to the adsorption of poly $(\mathrm{G})$ single-strands (Scheme 1C-left), and (ii) a large number of $2.7 \pm 0.5 \mathrm{~nm}$ height $\mathrm{A}$ aggregates, due to the formation of short GQ regions along the poly $(\mathrm{G})$ single-strands (Scheme 1C-middle). Additionally, in $\mathrm{K}^{+}$ solution, several GL15-poly $(\mathrm{G})$ molecules started to form compact aggregated morphologies (Fig. 5D, dashed circle). This adsorption pattern was only observed for the poly $(\mathrm{G})$ control with large incubation times, demonstrating that the presence of GL15 accelerates GQ formation and stabilisation, as previously observed for $\mathrm{d}\left(\mathrm{TG}_{4} \mathrm{~T}\right)$.

On increasing GL15-poly(G) incubation time from 0 to 28 days, the AFM images showed: (i) progressive decrease and disappearance of $\boldsymbol{r} \boldsymbol{P}$ structures due to the decrease in the number of GL15-poly(G) single strands, (ii) the occurrence and increase of a number of $\boldsymbol{A}$ spherical aggregates, due to the formation of short discrete GQ regions along the poly $(\mathrm{G})$ single strands, and (iii) some GL15-poly $(\mathrm{G})$ molecules started to form aggregated morphologies. With long incubation times (28 days incubation), in the presence of $\mathrm{Na}^{+}$ions the densely-condensed GL15-poly(G) molecules formed 
arrangements resembling diamond rings (Fig. 6C), while in the presence of $\mathrm{K}^{+}$ions almost no adsorption occurred (Fig. 6D), consistent with the formation of large GL15poly $(\mathrm{G})-\mathrm{GQ}$ aggregates.

GL15-poly $(G)$ had much reduced surface coverage, when compared with the poly $(G)$ control (Figs. 6A and 6B), demonstrating that GL15 binding to poly(G) accelerated GQ formation and stabilisation in the presence of both $\mathrm{Na}^{+}$and $\mathrm{K}^{+}$ions.

\subsubsection{Voltammetric characterisation}

$\operatorname{Poly}(G)$ control. The poly $(\mathrm{G})$ control redox behaviour was investigated in solutions of $100 \mu \mathrm{g} \mathrm{mL}^{-1} \operatorname{poly}(\mathrm{G})$ in the presence of $\mathrm{Na}^{+}$or $\mathrm{K}^{+}$ions, for different time periods. DP voltammograms of poly $(\mathrm{G})$ control in freshly prepared solutions (Figs. 5E- in $\mathrm{Na}^{+}$and $5 \mathrm{~F}-$ in $\mathrm{K}^{+}$ions), showed the occurrence of only one $\mathrm{G}$ oxidation peak, at $E_{\mathrm{pa}}=+0.90 \mathrm{~V}$, due to the oxidation of the guanine residues in the poly $(\mathrm{G})$ single strands. ${ }^{32}$

On increasing the poly $(\mathrm{G})$ control time from 0 to 28 days (Figs. $6 \mathrm{E}-$ in $\mathrm{Na}+$ and $6 \mathrm{E}-$ in $\mathrm{K}+$ ions), DP voltammograms showed: (i) the decrease and disappearance of the $\mathrm{G}$ oxidation peak of the poly $(\mathrm{G})$ single-strands, and (ii) the occurrence of a GQ oxidation peak, at $E_{\mathrm{pa}}=+0.98 \mathrm{~V}$, due to the formation and stabilization of poly $(\mathrm{G})-\mathrm{GQs}{ }^{31}$

GL15-poly(G) interaction. GL15-poly $(\mathrm{G})$ interaction was examined in solutions of 100 $\mu \mathrm{g}$ mL-1 poly $(\mathrm{G})$ incubated with $4.0 \mu \mathrm{M}$ GL15 in the presence of $\mathrm{Na}^{+}$and $\mathrm{K}^{+}$ions, during a range of incubation times, and showed redox behaviour similar to that of the GL15-d(TG $\left.\mathrm{TG}_{4} \mathrm{~T}\right)$ interaction. The GL15, G and GQ oxidation peaks of the GL15-poly(G) complex were compared with the oxidation peaks of poly $(\mathrm{G})$ and GL15 controls.

\section{(a) Freshly prepared solutions}

DP voltammograms of GL15-poly $(\mathrm{G})$ in freshly prepared solution (Figs. 5E- in $\mathrm{Na}^{+}$and $5 \mathrm{~F}-$ in $\mathrm{K}^{+}$ions) showed two oxidation peaks: (i) the GL15 oxidation peak, at $E_{\mathrm{pa}}=+$ $0.73 \mathrm{~V}$, and (ii) the $\mathrm{G}$ oxidation peak, at $E_{\mathrm{pa}}=+0.90 \mathrm{~V}$, due to oxidation of the guanine residues in the poly $(\mathrm{G})$ single-strands.

A large decrease in the GL15 oxidation peak current compared to the GL15 control took place (Figs. 5E, F-*), suggesting that GL15 interacted very rapidly with poly(G), resulting in a decreased number of free GL15 molecules. Reduced G oxidation peak currents were observed for GL15-poly $(\mathrm{G})$ compared with the poly $(\mathrm{G})$ control (Figs. 5Ein $\mathrm{Na}^{+}$and $5 \mathrm{~F}-$ in $\mathrm{K}^{+}$ions). This is due to fewer poly $(\mathrm{G})$ single strands available in the presence of GL15, and is caused by the formation of several short GL15-poly(G)-GQ regions, as observed in the AFM images (Fig. 5C, D). The GQ oxidation peak of the GL15-poly(G)-GQ regions was below the DP voltammetry detection limit.

\section{(b) Increasing incubation time}

On increasing the GL15-poly $(\mathrm{G})$ incubation time from 0 to 28 days (Figs. 6E- in $\mathrm{Na}^{+}$ and $6 \mathrm{~F}-$ in $\mathrm{K}^{+}$ions), the DP voltammograms showed: (i) the disappearance of the GL15 oxidation peak close to the signal/noise ratio, due to all free GL15 molecules binding to poly $(\mathrm{G})$, (ii) the decrease and disappearance of the G oxidation peak of the GL15-poly $(\mathrm{G})$ single strands, and (iii) the occurrence of the GQ oxidation peak, at $E_{\mathrm{pa}}=+0.97 \mathrm{~V}$, due to the formation and stabilization of GL15-poly $(\mathrm{G})-\mathrm{GQ}$ complexes. The phase of poly $(\mathrm{G})$ 
single strand self-assembly started with the generation of short GQ regions. These increased with incubation time, after which they started to fold into larger aggregates containing GQs, with the guanine residues more difficult to oxidise, shown by the smaller GQ oxidation peaks.

The GQ oxidation peak of the GL15-poly(G)-GQ after 28 days incubation (Figs. 6E$\mathrm{Na}^{+}$and $6 \mathrm{~F}-\mathrm{K}^{+}$ions) occurred at the same potential of the GQ oxidation peak of GL15$\mathrm{d}\left(\mathrm{TG}_{4} \mathrm{~T}\right)-\mathrm{GQ}$, at $E_{\mathrm{pa}}=+0.97 \mathrm{~V}$, (Figs. $4 \mathrm{~A} \cdot-\cdot$ in $\mathrm{Na}^{+}$and $4 \mathrm{~B}=\cdot$ in $\mathrm{K}^{+}$ions).

\section{Discussion}

GQ formation has been extensively studied in a variety of telomeric and other guaninerich sequences. The $\mathrm{d}\left(\mathrm{TG}_{4} \mathrm{~T}\right)$ sequence has been used as a model system for telomeric DNA in higher organisms, and both crystallographic and NMR structural data has shown that small molecules such as the anticancer drug daunomycin, bind to one face of the tetramolecular $\mathrm{d}\left(\mathrm{TG}_{4} \mathrm{~T}\right)$ parallel quadruplex. ${ }^{36}$ The present $\mathrm{AFM}$ data is entirely consistent with these findings with the phosphate-phosphate inter-strand distances found by X-ray crystallography of ca. $2.6 \mathrm{~nm}$ remarkably close to those found by AFM. A molecular model for the GL15-d( $\mathrm{TG}_{4} \mathrm{~T}$ ) parallel quadruplex (Fig. 4) shows that the nonintercalative end-stacking binding of GL15 has not altered the cross-diameter dimension of the GQ.

There is little data available on small-molecule binding to poly $(\mathrm{G})$ sequences, although such sequences are widely preva-lent in the human and other genomes at both DNA and RNA levels. Fibre diffraction data on poly $(\mathrm{G})$ has shown that in $\mathrm{K}^{+}$solution it consists of a continuous four-fold helix ${ }^{44}$, whose regularity may well be a consequence of the process of forming a polynucleotide fibre. Recent NMR studies ${ }^{45}$ have shown that short lengths of poly $(\mathrm{G})$ can form discrete GQ structures, with parallel topology and propeller loops, strikingly similar in form to the GQs formed by human telomeric DNA and RNA sequences in conditions of high concentration and in the crystalline state. The AFM studies reported here show that the small molecule GL15 induces the formation of discrete GQ complexes along the length of poly $(\mathrm{G})$ molecules, whose dimensions are essentially the same as those formed by $\mathrm{d}\left(\mathrm{TG}_{4} \mathrm{~T}\right)$, i.e. are indicative of short parallelfolded three-layer GQs. Further studies are needed to dissect out the detailed nature of these ligand complexes. The data presented here suggests that appropriately selective small molecules can form a number of GQ binding sites along a long length of homoguanosine RNA (or DNA) sequence, has implications for our understanding of the role played by GQs in cellular processes in both coding and non-coding regions in a genome and their perturbation by small molecule binding.

\section{Discussion}

GQ formation has been extensively studied in a variety of telomeric and other guaninerich sequences. The $\mathrm{d}\left(\mathrm{TG}_{4} \mathrm{~T}\right)$ sequence has been used as a model system for telomeric DNA in higher organisms, and both crystallographic and NMR structural data has shown that small molecules such as the anticancer drug daunomycin, bind to one face of the tetramolecular $\mathrm{d}\left(\mathrm{TG}_{4} \mathrm{~T}\right)$ parallel quadruplex. ${ }^{36}$ The present $\mathrm{AFM}$ data is entirely consistent with these findings with the phosphate-phosphate inter-strand distances found 
by X-ray crystallography of ca. $2.6 \mathrm{~nm}$ remarkably close to those found by AFM. A molecular model for the GL15-d(TG 4 T) parallel quadruplex (Fig. 4) shows that the nonintercalative end-stacking binding of GL15 has not altered the cross-diameter dimension of the GQ.

There is little data available on small-molecule binding to poly $(\mathrm{G})$ sequences, although such sequences are widely prevalent in the human and other genomes at both DNA and RNA levels. Fibre diffraction data on poly $(\mathrm{G})$ has shown that in $\mathrm{K}^{+}$solution it consists of a continuous four-fold helix ${ }^{44}$, whose regularity may well be a consequence of the process of forming a polynucleotide fibre. Recent NMR studies ${ }^{45}$ have shown that short lengths of poly $(\mathrm{G})$ can form discrete GQ structures, with parallel topology and propeller loops, strikingly similar in form to the GQs formed by human telomeric DNA and RNA sequences in conditions of high concentration and in the crystalline state. The AFM studies reported here show that the small molecule GL15 induces the formation of discrete GQ complexes along the length of poly $(\mathrm{G})$ molecules, whose dimensions are essentially the same as those formed by $\mathrm{d}\left(\mathrm{TG}_{4} \mathrm{~T}\right)$, i.e. are indicative of short parallelfolded three-layer GQs. Further studies are needed to dissect out the detailed nature of these ligand complexes. The data presented here suggests that appropriately selective small molecules can form a number of GQ binding sites along a long length of homoguanosine RNA (or DNA) sequence, has implications for our understanding of the role played by GQs in cellular processes in both coding and non-coding regions in a genome and their perturbation by small molecule binding.

\section{Conclusions}

The interactions of the GQ-targeting triazole-linked acridine ligand GL15 with the shortchain length Tetrahymena telom-eric DNA repeat sequence $d\left(\mathrm{TG}_{4} \mathrm{~T}\right)$ and with the poly $(G)$ sequence have been reported here at the single-molecule level, using a novel analytical approach that combines AFM and voltammetry. In the presence of GL15 GQ formation was detected by AFM via the adsorption of GL15-d(TG4 T)-GQ and GL15poly(G)-GQ small spherical aggregates and large GL15-poly(G)-GQ assemblies, and by DP voltammetry via GL15 and G oxidation peak current decrease and disappearance, and the occurrence of a GQ oxidation peak. The AFM and voltammetric results show that the GL15 molecule inter-acts with both sequences in a time-dependent manner. An excellent correlation was observed between the $\mathrm{d}\left(\mathrm{TG}_{4} \mathrm{~T}\right)$ and poly $(\mathrm{G})$ structural changes and redox behaviour, before and after interaction with GL15, and was directly influenced by the presence of monovalent $\mathrm{Na}^{+}$or $\mathrm{K}^{+}$ions in solution. These results are consistent with the interaction of triazole-linked acridine derivatives with terminal G-quartets in an individual GQ. The binding of the GL15 molecule to $\mathrm{d}\left(\mathrm{TG}_{4} \mathrm{~T}\right)$ and poly $(\mathrm{G})$ both strongly stabilized the GQs and accelerated GQ formation, in both $\mathrm{Na}^{+}$and $\mathrm{K}^{+}$ions solutions, although only the $\mathrm{K}^{+}$-containing solution promoted the formation of perfectly aligned tetra-molecular GQs. The combination of these two analytical techniques reveal to be very effective to study the effect of GL15 binding on GQ formation, and will trigger their use for a whole range of studies concerning drug interactions with DNA targets.

\section{ACKNOWLEDGMENT}


Financial support from Fundação para a Ciência e Tecnologia (FCT), Grant SFRH/BPD/92726/2013 (A.-M. Chiorcea-Paquim), Project Grant (A.D.R. Pontinha), projects PTDC/SAU-BMA/118531/2010, PTDC/QEQ-MED/0586/2012, PEst-C/EME /UI0285/2013 and CENTRO-07-0224-FEDER-002001 (MT4MOBI) (co-financed by the European Community Fund FEDER), FEDER funds through the program COMPETE Programa Operacional Factores de Competitividade is gratefully acknowledged. Work in the S.N. laboratory was supported by Programme Grant No. C129/A4489, from Cancer Research UK, and by the FP6 framework grant "Molecular Cancer Medicine" from the EU. S.S. was a Maplethorpe Fellow of The University of London.

\section{REFERENCES}

(1) Bochman, M.L.; Paeschke, K.; Zakian, V .A. Nat. Rev. Genet. 2012, 13, 770-780.

(2) Murat, P.; Balasubramanian, S. E. Curr. Opin. Genet. Dev. 2014, 25, 22-29.

(3) Neidle, S. In Therapeutic Applications of Quadruplex Nucleic Acids, Academic Press: Boston, 2012; chapter 2, pp. 21-42.

(4) Burge, S.; Parkinson, G. N.; Hazel, P.; Todd, A. K.; Neidle, S. Nucleic Acids Res. 2006, 34, 5402-5415.

(5) Du, Z.; Zhao, Y.; Li, N. Nucleic Acids Res. 2009, 37, 6784-6798.

(6) Eddy, J.; Maizels, N. Nucleic Acids Res. 2008, 36, 1321-1333.

(7) Bugaut, A.; Balasubramanian, S. Nucleic Acids Res. 2012, 40, 4727-4741.

(8) Todd, A. K., Johnston, M.; Neidle, S. Nucleic Acids Res. 2005, 33, 2901-2907.

(9) Bugaut A.; Balasubramanian, S. Nucleic Acids Res. 2012, 40, 4727-4741.

(10) Biffi, G.; Tannahill, D.; McCafferty, J.; Balasubramanian, S. Nature Chem. 2013, 5, 182-186.

(11) Henderson, A. et al. Nucleic Acids Res. 2013, 42, 860-869.

(12) Chen, Y; Yang, D. Curr. Protoc. Nucleic Acid Chem. 2012 Ch. 17, Unit 17.5.

(13) Oganesian, L.; Bryan, T.M. BioEssays 2007, 29, 155-165.

(14) Ohnmacht, S. A.; Neidle, S. Bioorg. Med. Chem. Lett. 2014, 24, 2602-2612.

(15) Sissi, C., Palumbo, M. Curr Pharm Des. 2014, 20, 6489-6509.

(16) Campbell, N. H.; Parkinson, G. N.; Reszka, A. P.; Neidle, S. J. Amer. Chem. Soc. 2008, 130, 6722-6724.

(17) Gunaratnam, M.; Greciano, O.; Martins, C.; Reszka, A. P.; Schultes, C. M.; Morjani, H.; Riou, J.-F.; Neidle S. Biochem. Phar-macol. 2007, 7, 679-689.

(18) Salvati, E.; Leonetti, C.; Rizzo, A.; Scarsella, M.; Mottolese, M.; Galati, R.; Sperduti, I.; Stevens, M. F. G.; D’Incalci, M.; Blasco, M.; Chiorinoo, G.; Bauwens, S.; Horard, B.; Gilson, E.; Stoppacci-arco, A.; Zupi, G.; Biroccio, A. J. Clin. Invest. 2007, 117, 3236-3247.

(19) Sparapani, S.; Haider, S. M.; Doria, F.; Gunaratnam, M.; Neidle, S. J. Am. Chem. Soc. 2010, 132, 12263-12272.

(20) Collie, G. W.; Sparapani, S.; Parkinson, G. N.; Neidle, S. J. Amer. Chem. Soc. 133, 2011, 2721-2728.

(21) Oliveira Brett, A. M.; Diculescu, V. C.; Chiorcea Paquim, A. M.; Serrano, S. H. P. In: Comprehensive Analytical Chemistry, Elec-trochemical Sensor Analysis, Alegret S., Merkoçi, A., Eds.; 2007, Ch. 20, Vol. 49, pp. 413-437. 
(22) Corduneanu, O.; Chiorcea Paquim, A.M.; Diculescu, V.C.; Fiuza, S.M.; Marques, M. P. M.; Oliveira Brett, A. M. Anal. Chem. 2010, 82, 1245-1252.

(23) Oliveira, S. C. B.; Chiorcea Paquim, A. M.; Ribeiro, S. M. Melo, A. T. P.; Vivan, M.; Oliveira Brett, A. M. Bioelectrochemistry 2009, 76, 201-207.

(24) Chiorcea Paquim, A. M.; Corduneanu, O.; Oliveira, S. C. B.; Diculescu, V. C.; Oliveira Brett, A. M. Electrochim. Acta, 2009, 54, 1978-1985.

(25) Pontinha, A. R.; Alves Jorge, D. S. M.; Chiorcea Paquim, A. M.; Diculescu, V. C.; Oliveira Brett, A. M. Phys. Chem. Chem. Phys. 2011, 13, 5227-5234.

(26) Diculescu, V. C.; Chiorcea Paquim, A. M.; Eritja R.; Oliveira Brett, A.M. J. Electroanal. Chem. 2011, 656, 159-166.

(27) Diculescu, V. C.; Chiorcea Paquim, A. M.; Eritja R.; Oliveira Brett, A. M. J. Nucleic Acids, 2010, ID 841932.

(28) Chiorcea Paquim, A. M.; Santos, P. V.; Oliveira Brett, A. M.; Electrochim. Acta 2013, 110, 599-607.

(29) Chiorcea Paquim, A. M.; Santos, P.; Diculescu, V. C.; Eritja R.; Oliveira Brett, A. M.; In: Guanine quartets - structure and

application, Ed. G.P. Spada, 2013, pp. 100-109.

(30) Chiorcea Paquim, A. M.; Santos, P. V.; Eritja, R.; Oliveira Brett, A. M.; Phys. Chem. Chem. Phys. 2013, 15(23), 9117-9124.

(31) Chiorcea Paquim, A. M.; Oliveira Brett, A. M.; Electrochim. Acta 2014, 126, $162-$ 170.

(32) Chiorcea Paquim, A. M.; Pontinha, A. D. R.; Oliveira Brett, A. M. Electrochem. Commun. 2014, 45, 71-74.

(33) Pontinha, A. D. R.; Chiorcea Paquim, A. M.; Eritja, R.; Oliveira Brett, A. M. Anal. Chem. 2014, 86, 5851-5857.

(34) Pontinha, A. D. R.; Sparapani, S.; Neidle, S.; Oliveira-Brett, A. M. Bioelectrochemistry 2013, 89, 50-56.

(35) Laughlan, G.; Murchie, A. I.; Norman, D. G.; Moore, M. H.; Moody, P. C.; Lilley, D. M.; Luisi, B.; Science 1994, 265, 520-524.

(36) Clark, G. R.; Pytel, P. D.; Squire, C. J.; Neidle, S.; J. Am. Chem. Soc. 2003, 125, 4066-4067.

(37) Pagano, B.; Fotticchia, I.; Tito, S.; Mattia, C. A.; Mayol, L.; Novellino, E.; Randazzo, A.; Giancola, C.; J. Nucleic Acids, 2010, ID 247137.

(38) Chiorcea-Paquim, A.-M.; Oretskaya, T. S.; Oliveira-Brett, A. M.; Biophys. Chem. 2006, 121, 131-141.

(39) Brett, C. M. A.; Oliveira Brett, A. M.; Serrano, S. H. P.; J. Electroanal. Chem. 1994, 366, 225-231.

40) Mergny, J. L., Cian, A., Ghelab, A., Sacca, B., Lacroix, L.; Nu-cleic Acids Res. 2005, 33, 81-94.

(41) Haider, S. M.; Parkinson, G. N.; Neidle, S. J. Mol. Biol. 2003, 326, 117-125.

(42) Campbell, N. H.; Parkinson, G. N.; Reszka, A. P.; Neidle, S. J. Am. Chem. Soc. 2008, 130, 6722-6724.

(43) Dai, J.; Carver, M.; Hurley, L. H.; Yang, D. J. Am. Chem. Soc. 2011, 133, 1767317680.

(44) Arnott, S.; Chandrasekaran, R.; Marttila, C. M. Biochem. J. 1974, 141, 537-543.

(45) Sengar, A.; Heddi, B.; Phan, A. T. Biochemistry. 2014, 53, 7718-7723. 
Graphical for the Table of contents.

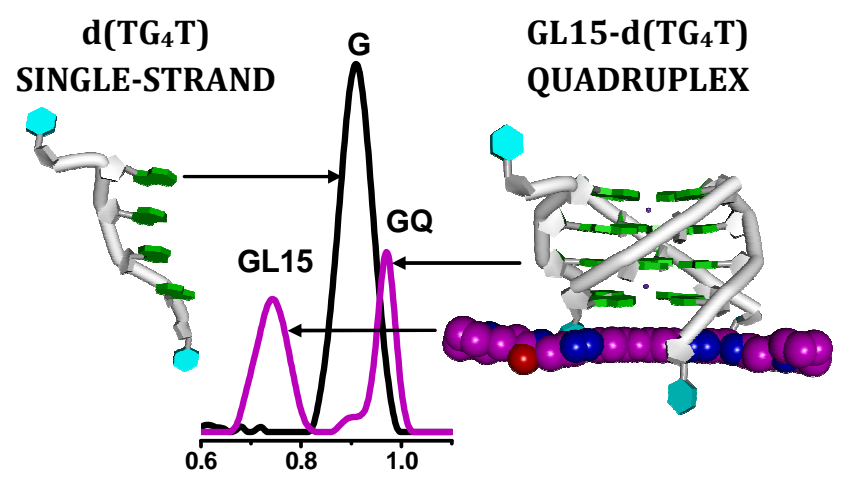

